\title{
Current Diagnosis and Treatment of Gastric Cancer: Where East Meets West
}

Every year more than one million people are diagnosed with gastric cancer throughout the world. About $75 \%$ of these patients die due to the disease, making gastric cancer the No. 2 cancer death cause in the world. Incidence differs a lot per continent. The highest incidence is found in men in northeast Asia with about 70 cases per 100,000 people per year (Japan, Korea, and China). Europe and South America show intermediate incidence rates, whereas North America, Africa, South Asia, and Australia are considered low-incidence regions (4-10 cases per 100,000).

Prevention strategies to reduce gastric cancer include improvement of sanitation, high intake of fresh fruits and vegetables, safe food-preservation methods, and avoidance of smoking. Although the frequency of distal gastric cancer has declined, the incidence of proximal gastric cancer has risen. Unlike distal gastric cancer, development of proximal cancer is mainly related to gastroesophageal reflux and obesity. Classification and strategies for junctional tumors have improved and are now better defined.

In countries with high incidence, like Japan, screening programs are cost-beneficial, leading more often to early detection and better prognosis. In countries without screening programs, gastric cancer is often diagnosed in an advanced stage and generally survival is only $20-25 \%$. Palliative surgery, especially in Western countries, is very common; however, without hard evidence, treatment choices are still made individually, based on expert opinions.

In Eastern countries, surgery for gastric cancer is well defined and developed, and performed in centers that in Western countries are considered very large. Nowadays, however, Western countries are centralizing gastric cancer treatment more and more, which is leading to better outcomes.
For a long time, surgery alone used to be the standard treatment for curable advanced gastric cancer. However, times have changed. Although different schedules and opinions exist between continents and countries, (neo)adjuvant treatment with chemotherapy and/or radiotherapy have been shown to improve survival outcome and are now also considered as standard. The optimal regimens are continuously under investigation as well as tailoring of treatment. Another expression of tailoring treatment is found within unraveling molecular mechanisms by pathologists and accurate preoperative staging. Furthermore, the extent of surgery is becoming more and more individualized by the use of sentinel node techniques, laparoscopic surgery, and the extent of lymph node dissection.

In order to prepare the tailored treatment, preoperative staging is of great importance. Fortunately, diagnostic tools are improving continuously and the latest version of the UICC/AJCC TNM staging system for gastric cancer improves the $\mathrm{T}$ designations and the prognostic stratification of the $\mathrm{N}$ status, and has added clearer definitions for M1 disease.

Nevertheless, the treatment between Eastern and Western countries differs. In this thematic issue of Digestive Surgery, we invited experts in the field of gastric cancer from the East and the West to give their evidence-based view as well as their expert opinion on topics that are still under discussion. We are very pleased that the contributing authors have provided us with excellent papers dealing with the issues that we think are 'hot' in the treatment of gastric cancer.

Henk H. Hartgrink, Leiden Yasuhiro Kodera, Nagoya

\section{KARGER}

E-Mail karger@karger.com

www.karger.com/dsu (c) 2013 S. Karger AG, Basel

0253-4886/13/0302-0091\$38.00/0 